\title{
'Do no harm': an intuitive decision tool to assess the need for gastrointestinal endoscopy
}

\section{다 (1) $\odot$}

Authors

Amnon Sonnenberg ${ }^{*}, 1,2$, Heiko Pohl ${ }^{*}, 3,4$

Institutions

1 Gastroenterology Section, Portland VA Medical Center

2 Division of Gastroenterology and Hepatology, Oregon Health \& Science University, Portland, Oregon, United States

3 Gastroenterology Section, VA Medical Center, White River Junction, Vermont, United States

4 Division of Gastroenterology, Dartmouth-Hitchcock Medical Center, Lebanon, New Hampshire, United States
Bibliography

DOI https://doi.org/10.1055/a-0826-4432 |

Endoscopy International Open 2019; 07: E384-E388

(C) Georg Thieme Verlag KG Stuttgart · New York

ISSN 2364-3722

Corresponding author

Amnon Sonnenberg, MD, MSc, Portland VA Medical Center, P3-GI, 3710 SW US Veterans Hospital Road, Portland, OR

97239, USA

Fax: +1-503-220-3426

sonnenbe@ohsu.edu

\section{Introduction}

A fundamental principle of medical ethics states: "Above all, do no harm" [1]. Such maxim serves as a reminder to physicians that they need to be aware of the potential harms of their medical interventions. Because almost all medical interventions are associated with some downsides and costs, however, it is impractical to observe such maxim literally and without also balancing the benefit or effectiveness of an intervention with its cost.

Cost-effectiveness analyses have been used to develop guidelines of when to perform an endoscopy [2-5]. Cost-effectiveness is generally calculated from a societal perspective to account for all personal and collective monetary costs that arise from an endoscopic procedure. The effectiveness of the procedure is measured in life-years saved through endoscopy, which may also become adjusted to their quality as quality adjusted life-years (QALYs). Cost-effectiveness analyses have proven helpful in forming national policies or professional guidelines, but are impractical as instruments for dealing with individual patients. It would be difficult to account at the bedside for all the potential costs of endoscopy and its probable impact on life expectancy. Guidelines by professional societies, such as the American Society for Gastrointestinal Endoscopy and European Society of Gastrointestinal Endoscopy, provide general rules for managing common medical conditions. They cannot cover all intricacies encountered in the daily routine of managing individual patients. Apart from a societal perspective of

\footnotetext{
* Drs. Sonnenberg and Pohl: These authors contributed equally.
}

cost-effectiveness analyses and the general principles outlined in guidelines, a physician would also be interested in addressing the patient's individual risks, needs, expectations, fears, or consider his/her own estimates of the downsides, limitations, costs, and benefits of the planned procedure.

The aim of this editorial is to present an intuitive decision tool that would be applicable in clinical practice without involving complex mathematical analysis. As a bedside tool, it would focus on the individual patient's and endoscopist's perspective rather than on abstract concepts detached from clinical practice, such economic costs or QALYs. The outcome of the analysis would be expressed as threshold probabilities of when to perform gastrointestinal endoscopy.

\section{Cost-benefit considerations in endoscopy}

A decision against or in favor of an endoscopic procedure is associated with three questions. First, what are the costs of the planned procedure? The costs include not only procedural and professional fees, but also risk of potential adverse events (AEs). From a patient's perspective, the costs also include fears of a medical procedure and discomfort experienced during endoscopy, as well as the loss in time, expense of travel, and the overall inconvenience of a physician visit. Second, what is the potential health benefit of the procedure with respect to diagnosis and therapy? Third, how does one weigh the costs against the benefit of endoscopy? - Table 1 lists the individual factors that may potentially affect the decision against or in favor of endoscopy from the perspective of the endoscopist, as well as the patient. Besides their own perspective, endoscopists 
Table 1 Individual factors that affect the decision against or in favor of endoscopy.

\begin{tabular}{|c|c|c|}
\hline & Endoscopist perspective & Patient perspective \\
\hline $\begin{array}{l}\text { Against endoscopy } \\
\text { "COST" }\end{array}$ & $\begin{array}{l}\text { - Adverse events } \\
\text { - Procedural costs } \\
\text { - Availability of alternative tests or procedures }\end{array}$ & $\begin{array}{l}\text { - Fear of procedure } \\
\text { - Discomfort } \\
\text { - Inconvenience } \\
\text { - Opportunity costs }{ }^{1} \\
\text { - Monetary costs }\end{array}$ \\
\hline $\begin{array}{l}\text { In favor of endoscopy } \\
\text { "BENEFIT" }\end{array}$ & $\begin{array}{l}\text { - Diagnostic gain } \\
\text { - Therapeutic gain } \\
\text { - Legal concerns } \\
\text { - Monetary incentives }\end{array}$ & $\begin{array}{l}\text { - Resolution of fears, comfort, and reassurance } \\
\text { - Symptom relief }\end{array}$ \\
\hline
\end{tabular}

would be able to appreciate not only their own, but also their patients' perspective. In the current analysis, we use the term "cost" in reference to all factors that affect the decision against endoscopy and not just monetary costs. Similarly, the term "benefit" is used to indicate all factors that affect the decision in favor of endoscopy.

\section{Known benefit and known cost}

A more applicable variation of the fundamental principle of medical ethics from above is captured by the rule that "the cure should not be worse than the disease" [8-9]. In context of endoscopy, one would not perform an endoscopic procedure unless the benefit of endoscopy (B) exceeds its costs (C), that is $B>C$. For example, a young man with epigastric pain is being seen by a gastroenterologist for the first time. The gastroenterologist entertains a brief list of potential differential diagnoses, including reflux disease, peptic ulcer, or non-ulcer dyspepsia. Confirming any such diagnosis would be considered worthwhile spending on esophagogastroduodenoscopy (EGD), by far outweighing its associated costs. Although the overall costs of endoscopy may stay the same, its impact and benefit would be even larger in patients with alarm symptoms, such as dysphagia, weight loss, or melena, in whom esophageal cancer, gastric cancer, or bleeding varices are being entertained as potential diagnoses. Other examples abound in clinical practice, especially in emergency situations, where the benefit and the cost of a planned endoscopic procedure are clear-cut and easy to assess.

\section{Unknown benefit and known cost}

At the onset of a planned procedure, its potential benefit is sometimes difficult to state with certitude. Instead of using an absolute value of benefit, one would use an expected value of benefit, which corresponds to the benefit value multiplied by its probability of occurrence. The initial equation from above changes to $\mathrm{p}_{\mathrm{b}} \cdot \mathrm{B}>\mathrm{C}$, where $\mathrm{p}_{\mathrm{b}}$ represents the probability for the occurrence of a beneficial endoscopy outcome. Solving the equation for $\mathrm{p}_{\mathrm{b}}>\mathrm{C} / \mathrm{B}$ yields a threshold probability for when to schedule an endoscopy. In general, a low threshold probability is associated with a preferred management option [6-7].
The young man from above may have already undergone two previous unremarkable EGDs. Instead of using an absolute value of benefit (B), the endoscopist would need to adjust the benefit by its probability of occurrence. Now, the expected benefit $\left(p_{b} \cdot B\right)$ of a repeat EGD would be considered low, because it is unlikely that the endoscopy will reveal a treatable cause and benefit the patient. In a revised assessment, the gastroenterologist would focus on the probability for a beneficial endoscopy outcome. The left panel of $\mathbf{\nabla i g} \mathbf{1}$ depicts the relationship between probability and benefit at a known (fixed) cost. The greater the benefit, the lower the threshold for performing an endoscopy. For illustrative purposes, cost and benefit are expressed in dollar amounts. It is assumed that an EGD would cost $\$ 500$. Any benefit rising from $\$ 500$ to $\$ 10,000$ would lower the threshold probability for endoscopy from $100 \%$ to $5 \%$, respectively. The general pattern of such inverse relationship between threshold probability and endoscopy remains unaffected by the amount of costs associated with endoscopic procedure itself.

Colonoscopy with polypectomy accounts for overall greater costs than EGD. Most gastroenterologists assume that the benefit of preventing future colorectal cancer by far outweighs the costs of a colonoscopy. For instance, if the overall future benefit exceeds the costs 50 - or 100 -fold, the threshold probability for a beneficial colonoscopy drops to $2 \%$ or $1 \%$, respectively. The endoscopist does not even need to express cost and benefits in any monetary terms, but only estimates the ratio of cost over benefit. The cost/benefit ratio then immediately translates into a probability threshold of when to perform an endoscopy, as depicted in the lower panel of $>$ Fig. 1. A very low threshold would suggest doing the endoscopy at the drop of the proverbial hat. A high threshold close to $100 \%$ or even higher would argue against endoscopy, as its cost may well outweigh the expected benefit.

\section{Unknown benefit and unknown cost}

If the benefits and costs of an endoscopic procedure are subject to pre-procedural uncertainty, both their estimates need to be weighted by their probability of occurrence. The initial equation changes once more to $\mathrm{p}_{\mathrm{b}} \cdot \mathrm{B}>\mathrm{p}_{\mathrm{c}} \cdot \mathrm{C}$, where $\mathrm{p}_{\mathrm{b}}$ and $\mathrm{p}_{\mathrm{c}}$ represent the probability for the occurrence of a beneficial or ad- 


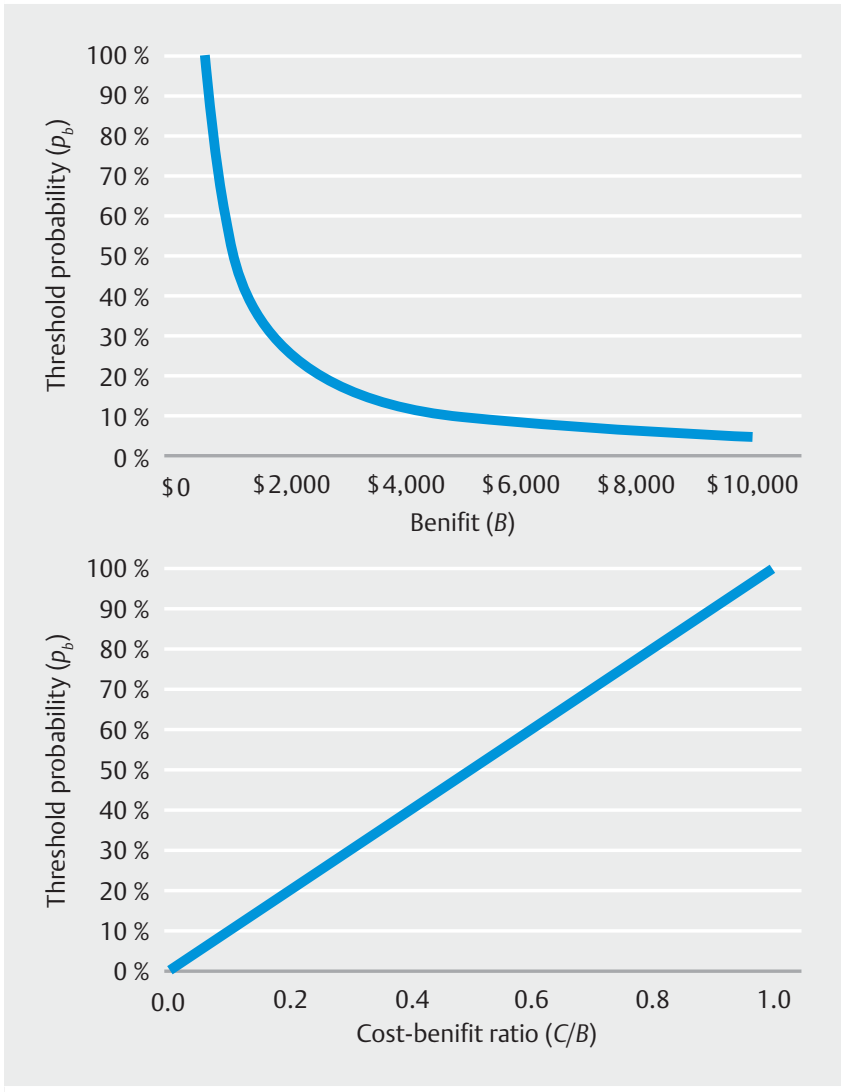

- Fig. 1 Upper panel: Influence of benefit on the threshold probability for performing endoscopy. Lower panel: Linear relationship between threshold probability and cost/benefit ratio.

verse outcome, respectively. Both cost and benefit become weighted by their respective probability of occurrence. Instead of a threshold probability, one can use this equation to calculate a probability ratio $\mathrm{p}_{\mathrm{b}} / \mathrm{p}_{\mathrm{c}}>\mathrm{C} / \mathrm{B}$ for a decision in favor or against endoscopy.

Consider the example of a patient with a large, flat adenoma in the right colon found incidentally during a routine screening colonoscopy. On the benefit side, a mucosal resection during colonoscopy would spare the patient all the costs, inconveniences, and potential risks associated with a right-sided hemicolectomy [10]. On the cost side, there is substantial risk of perforating the colon or causing some major bleeding and the potential administrative and legal ramifications of such AEs. The endoscopist may gauge the costs to be 2-fold higher than the benefits. Therefore, the chances of successful mucosal resection by this individual endoscopist need to be at least twofold higher than the chances of a major complication: $p_{b} / p_{c}>C / B=$ 2 , that is, $p_{b}>2 p_{c}$. As this example also illustrates, such estimates would be based on the skillset of the individual endoscopists and the circumstances of their practice.

- Fig. 2 depicts the relationship between the probability ratio and the cost/benefit ratio. Whenever the probability ratio exceeds the cost ratio, as in the area above the diagonal line, the endoscopy is worthwhile doing. Whenever the probability ratio falls below the diagonal line, the endoscopy is not worth-

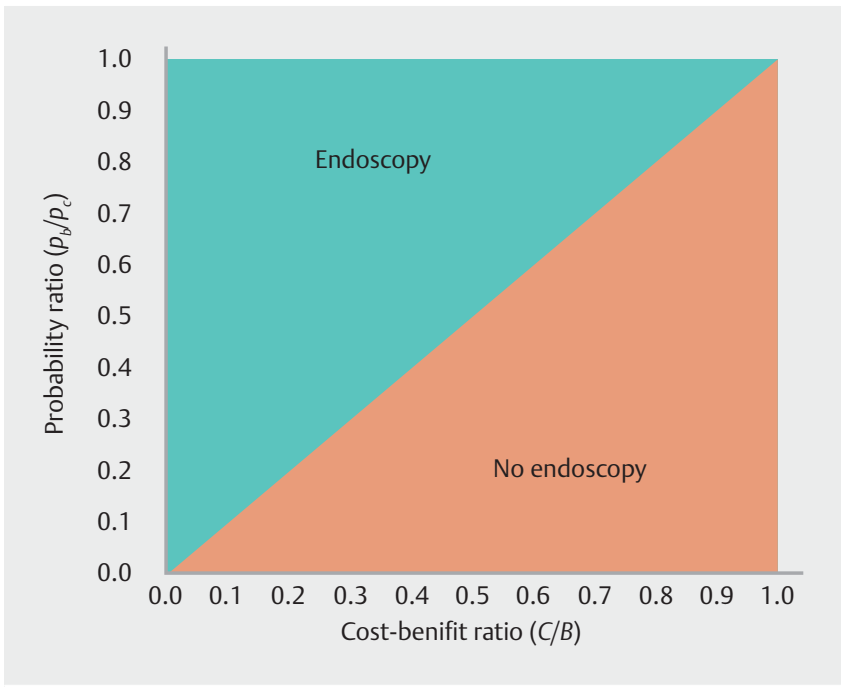

- Fig. 2 Influence of the cost/benefit ratio on the probability ratio and the decision against or in favor of endoscopy.

while doing. On the one hand, with a low cost/benefit ratio, as in the left portion of the figure, the decision in favor of endoscopy is relatively insensitive to the probability of its successful outcome. The endoscopy would be indicated in most instances, unless there is a substantial risk associated with the planned procedure, that is, a high probability of future costs and complications. In a patient with acute upper gastrointestinal bleeding, for instance, an emergency endoscopy to find the bleeding site and achieve hemostasis seems almost always indicated, independently of the precise magnitude of the a-priori chance of finding and treating the bleeding site. Such assessment would only be mitigated by a high risk for adverse events associated with the endoscopy. On the other hand, with a high cost/benefit ratio, as in the right portion of the figure, the decision in favor of endoscopy becomes quite sensitive to the probability of a successful outcome. The endoscopist would not perform the endoscopy, unless its probability of success is high and compares favorably with the probability of future costs. For instance, endoscopic retrograde cholangiopancreatography (ERCP) with papillotomy can lead to acute pancreatitis, duodenal perforation, and bleeding as serious AEs. Before embarking on an ERCP in a patient with cholestasis and suspected choledocholithiasis, endoscopists generally want to ascertain the presence of biliary gallstones by other means, such as imaging of the bile ducts using endoscopic ultrasound or magnetic resonance cholangiography, to ascertain a high probability of a beneficial outcome [11].

\section{Utility and limitations of threshold analysis}

Albert Einstein supposedly quipped "not everything that can be counted counts, and not everything that counts can be counted" [12]. The downsides of endoscopy include financial expenditures, as well as a variety of physical and mental discomforts. 
Endoscopists may find it difficult to express all downsides, AEs, and long-term sequelae of a planned endoscopic procedure in monetary terms. They may find it similarly difficult to capture all the possible benefits of endoscopy in a common currency of money gained or life-years saved. Any type of detailed accounting would be impossible to achieve during patient encounters in the office or at the bedside, where the multitude of emergent medical problems require quick resolutions. The contents of $>$ Table 1 serve as a summary of the factors to consider when deciding in favor or against an endoscopy. In their decision-making, endoscopists are not meant to itemize all these costs and benefits for each individual patient. Here, endoscopists are rather encouraged to think in broad categories and develop a gestalt of the overall costs and benefits that will arise from the planned endoscopy. The threshold analysis serves to make best use of the clinician's own current knowledge in deriving the most sensible medical decision. This intuitive decision tool is meant to maximize the utilization of the endoscopist's subjective assessment of the acute clinical situation. Numerical precision is not the issue. Rather than accumulate all the individual costs and benefits of endoscopy, the present type of analysis only relies on a comparison of the relative magnitude of the cost and benefit. The absolute magnitude of the cost or benefit value is difficult to gauge. By comparison, their relative value is much easier to estimate. The estimated cost/benefit ratio immediately translates into a threshold probability or probability ratio. Compared with a cost-effectiveness ratio, probability values are also more intuitive to medical practice, because they reflect on a parameter that the physicians constantly deal with in their daily practice.

There are several potential limitations associated with the proposed decision tool. Like any medical test, assessment of the cost/benefit ratio and its translation into a probability threshold or probability ratio is not infallible and open to bias. There are gastroenterologists who, based on previous experience, harbor great concerns about missing potential diagnoses and may have a low threshold for initiating any endoscopic procedure. Others may have a high threshold for initiating an endoscopy, because they are realistic or very critical about their own chances for endoscopic success.

Endoscopists may only consider the costs of the immediate procedure and ignore the potential costs of AEs or future failures. If their professional income is directly linked to the number of endoscopies, from the perspective of such endoscopist, some of the endoscopy costs may become shifted towards the benefit side, resulting in a professional bias in favor of endoscopy. Many investigators, who studied the utilization of EGDs and colonoscopies in various countries, found that half or more of all endoscopies may represent overuse and may have been unnecessary [13-17]. Overuse of endoscopy pertains even to gastroenterologists, who do not derive any financial benefit from repeat endoscopy [18]. Being familiar with endoscopic procedures, endoscopists may partly discount the discomfort or anxiety felt by patients and assign lesser relevance to potential AEs. There is a proverb that says, to someone with a hammer, all problems look like a nail. The corresponding "law of the instrument" relates to the underlying cognitive bias of over-reliance on a familiar tool [19]. However, such professional bias is not restricted to gastroenterologists, but applies similarly to surgeons who tend to treat vague upper abdominal with unnecessary cholecystectomy, or to gynecologists who tend to treat vague lower abdominal symptoms with unnecessary hysterectomy [20-21].

\section{Conclusion}

In summary, we have suggested the use of threshold analysis to model decision-making in gastrointestinal endoscopy. As with any test, the results of the analysis are sensitive to bias and error in judgement. The advantage of the decision tool relates to its reliance on the endoscopist's personal experience. Numerical precision is not required, and little if any calculation is needed to derive a threshold probability based on comparative estimates and considerations of magnitude only.

\section{Competing interests}

None

\section{References}

[1] Smith CM. Origin and uses of primum non nocere - above all, do no harm! J Clin Pharmacol 2005; 45: 371 - 377

[2] Sonnenberg A, Delcò F, Inadomi JM. Cost-effectiveness of colonoscopy in screening for colorectal cancer. Ann Intern Med 2000; 133: $573-584$

[3] Naber SK, Kuntz KM, Henrikson NB et al. Cost effectiveness of agespecific screening intervals for people with family histories of colorectal cancer. Gastroenterology 2018; 154: 105-116

[4] Pohl H, Sonnenberg A, Strobel S et al. Endoscopic versus surgical therapy for early cancer in Barrett's esophagus: a decision analysis. Gastrointest Endosc 2009; 70: 623-631

[5] Yeh JM, Hur C, Ward Z et al. Gastric adenocarcinoma screening and prevention in the era of new biomarker and endoscopic technologies: a cost-effectiveness analysis. Gut 2016; 65: 563-574

[6] Pauker SG, Kassirer JP. The threshold approach to clinical decision making. N Engl J Med 1980; 302: 1109-1117

[7] Sonnenberg A. Decision analysis in clinical gastroenterology. Am J Gastroenterol 2004; 99: 163-169, 400

[8] Wiktionary contributors. The cure is worse than the disease. Wiktionary, The Free Dictionary. Available at https://en.wiktionary.org/ $w /$ index.php?title=the_cure_is_worse_than_the_disease\&ol$\mathrm{did}=43298282$ [Accessed March 22, 2018]

[9] Wikipedia contributors. latrogenesis. Wikipedia, The Free Encyclopedia. Available at https://en.wikipedia.org/w/index.php?title=latrogenesis\&oldid=826855182 [Accessed March 22, 2018]

[10] Klein A, Bourke MJ. How to perform high-quality endoscopic mucosal resection during colonoscopy. Gastroenterology 2017; 152: 466 471

[11] Sonnenberg A, Enestvedt BK, Bakis G. Management of suspected choledocholithiasis: A decision analysis for choosing the optimal imaging modality. Dig Dis Sci 2016; 61: $603-609$

[12] Robinson A. Thus spake Einstein. Aeon; March 12, 2018. Available at https://aeon.co/essays/why-do-we-love-to-quote-and-misquotealbert-einstein [Accessed March 22, 2018] 
[13] Burnand B, Harris JK, Wietlisbach V et al. Use, appropriateness, and diagnostic yield of screening colonoscopy: an international observational study (EPAGE). Gastrointest Endosc 2006; 63: 1018-1026

[14] Argüello L, Pertejo V, Ponce $\mathrm{M}$ et al. The appropriateness of colonoscopies at a teaching hospital: magnitude, associated factors, and comparison of EPAGE and EPAGE-II criteria. Gastrointest Endosc 2012; 75: $138-145$

[15] Hassan C, Bersani G, Buri L et al. Appropriateness of upper-Gl endoscopy: an Italian survey on behalf of the Italian Society of Digestive Endoscopy. Gastrointest Endosc 2007; 65: 767 - 774

[16] Keren D, Rainis T, Stermer E et al. A nine-year audit of open-access upper gastrointestinal endoscopic procedures: results and experience of a single centre. Can J Gastroenterol 2011; 25: 83-88
[17] Pohl H, Robertson D, Welch HG. Repeated upper endoscopy in the Medicare population: a retrospective analysis. Ann Intern Med 2014; 160: $154-160$

[18] Rubenstein JH, Pohl H, Adams MA et al. Overuse of repeat upper endoscopy in the Veterans Health Administration: a retrospective analysis. Am J Gastroenterol 2017; 112: 1678-1685

[19] Wikipedia contributors. Law of the instrument. Wikipedia, The Free Encyclopedia. Available at https://en.wikipedia.org/wiki/Law_of_ the_instrument [Accessed March 22, 2018]

[20] Longstreth GF, Wilson A, Knight K et al. Irritable bowel syndrome, health care use, and costs: a U.S. managed care perspective. Am J Gastroenterol 2003; 98: 600-607

[21] Cole JA, Yeaw JM, Cutone JA et al. The incidence of abdominal and pelvic surgery among patients with irritable bowel syndrome. Dig Dis Sci 2005; 50: $2268-2275$ 